\title{
Application of Innovative Technologies in the Production of Malting
}

\author{
G.Baigaziyeva $^{1}$, S. Shintasova ${ }^{1}$ \\ ${ }^{1}$ Almaty technological university, Republic of Kazakhstan \\ e-mail: bgulgaishailias@mail.ru
}

\begin{abstract}
Currently new ways of impact the barley grain are being sought to increase the germination, reduce the germination time, increase enzyme activity and improve the quality of ready-made malt. The use of ion-ozone explosive cavitation to soak brewing barley in the process of malting gives a chance to reduce the duration of soaking and improve the technological performance
\end{abstract}

Keywords - ion-ozone explosive cavitation, malting, barley, soaking, moisture, extractivity, germination energy, germination capacity.

\section{Introduction}

Soaking of the barley is a crucial stage of the malting process, as its conditions impact the germination process, its duration, the losses during the process, and the quality of the produced malt.

This technological process cannot be regarded independently in isolation from the general process of malting, it is only its first stage. The soaking stage in addition to supplying grain with water must be accompanied by the supply of sufficient oxygen to the grain. The more the grain absorbs water, the more intensive the metabolic processes take place and the greater the need for oxygen. Therefore, the minimum level of oxygen must be maintained inside the grain, which corresponds to a dynamic equilibrium between the lowest limit of consumption of its germ and the supply of oxygen from the external environment. Otherwise, the grain begins to spend its spare substances (carbohydrates) to cover the energy it needs, in such case instead of water and carbon dioxide the alcohol and a number of intermediate products such as aldehydes, acids and ethers are produced, which poisonous to germ, and has harmful impacts on the next stage - germination of grain.

Typically, the goal of soaking process is to cleanse the grain of light impurities, disinfect the grain, and, most importantly, supply the optimum humidity for malting process.

Thus, the following requirements should be based on the development of various methods of soaking the barley:

1) achieving the necessary humidity;

2) maintaining the optimum temperature;

3) supply of oxygen and removal of carbon dioxide [1].

There is a method of processing, where several ways of exposure a biological object are combined: soaking, thermal influence, vibration, and cavitation. Seeds that have been acoustically cavitated have highly germination capacity, as well as accelerated development, which makes it possible to either improve the quality of products from sprouted grain, or shorten the sprouting period and reduce its cost at the initial quality level [2].

With the aim of speeding up the soaking process, we developed a universal ion-ozone explosive cavitation plant for processing barley grain and is currently at the stage of organization industry (Figure 1). 


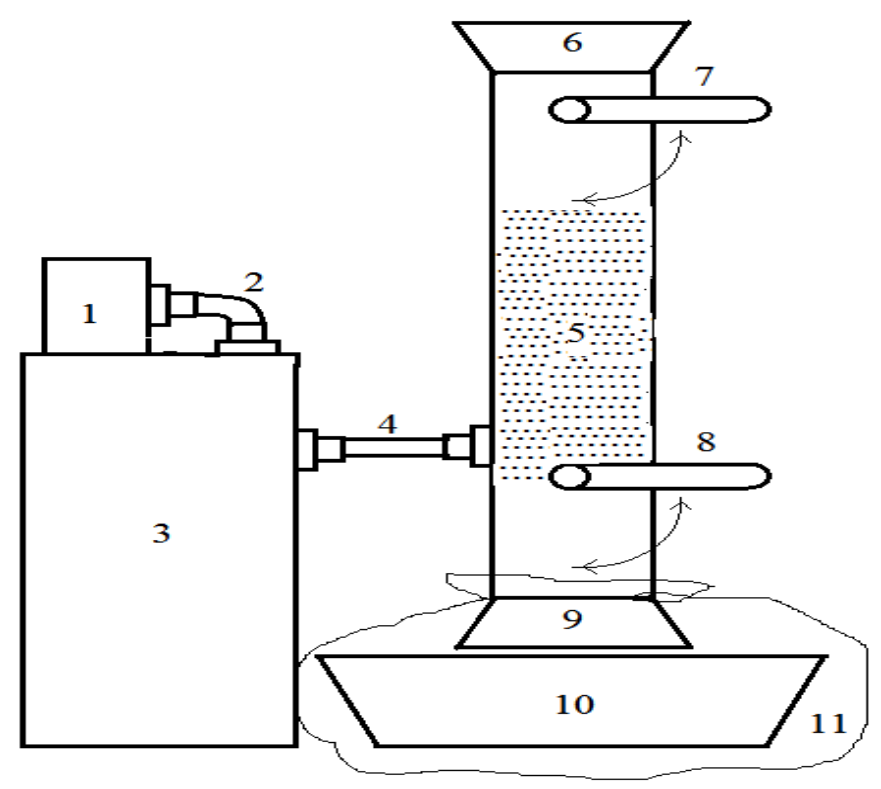

Fig.1:Ion-Ozone Explosive Cavitation Installation

The ion-ozone explosion cavitation installation in accordance with the drawing consists of the following elements:

1. The compressor

2. Air line

3. Ion-ozone installation

4. Pipeline for ion-ozone mixture

5. Cavitation installation

6. Feeding pipe grain

7. Grain filling valve

8. Pressure relief valve

9. Grain discharge hose

10. Capacity - grain collector

11. The grain trap.

Scientists from Italy and Russia are engaged in research in this field of science. The journal of the Massachusetts Institute of Technology talks about a revolutionary experiment that can completely change the technology of brewing.

The object of their attention was the cavitation, the process of vaporization and subsequent collapse of vapor bubbles with simultaneous condensation of vapor in the flow of liquid. Actually this process occurs during the decrease of the pressure in the liquid - the liquid boils, and then, as the pressure increases, the vapor condenses [3].

In this study, the basis for processing barley grain is the creation of a sharp drop in the calculated excess pressure during ion-ozone treatment of barley. As a result, with a sudden release of excess pressure to atmospheric pressure, ozone explodes, which increases the efficiency of the sudden pressure drop in the explosive cavitation installation, namely, the cavitation of the grain. With a sudden release of excess pressure from 4-8 atm. to the atmospheric pressure of the environment, an explosion-cavitation strike occurs. In these processes, there is no need to use cavitation destructors. The installation is simple in design, as well as has high working resources due to the lack of moving and electrical elements.

The work of the ion-ozone explosion-cavitation installation for barley grain processing is distinguished by its versatility with respect to the feedstock, as well as its compactness and very high working life, in addition to gives a great advantage in the price / quality / productivity ratio, in comparison to all existing plants [4]. 


\section{Objects and Methods of Investigation}

Research was carried out in the Research Laboratory of Innovative Technology of Food and Processing Industries of Almaty Technological University.

The objects of research were:

- brewing barley of Class I;

- ion-ozone explosion cavitation installation.

Research methods:

- determination of moisture content of barley grain according to State standard13586.5-93;

- determination of pest infestation according to State standard 13586-4-83;

- determination of extractivity according to State standard 12136-77;

- determination of energy and germination capacity in accordance with State standard 10968-88.

\section{Results and Discussion}

We carried out initial studies on the effect of ion-ozone explosion-cavitation processes on the time and degree of soaking of barley grain.

Ion-ozone explosive cavitation was applied before soaking barley grain. As a control, not processed sample of grain was taken. The experiments were carried out under treatment conditions indicated in Table 1.

TABLE I: Effect of Processing Regimes onto Technological Parameters of Barley Grain

\begin{tabular}{|c|c|c|c|c|c|c|c|c|c|c|}
\hline \multirow[b]{2}{*}{ Samples } & \multicolumn{5}{|c|}{ Processing regime } & \multicolumn{5}{|c|}{ Technological parameters } \\
\hline & $\begin{array}{l}0 \\
0 \\
\overrightarrow{0} \\
\overline{0} \\
+\end{array}$ & 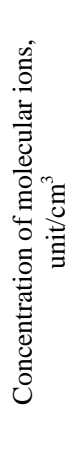 & 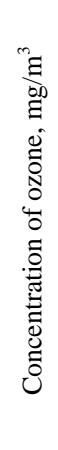 & 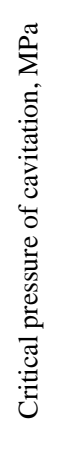 & 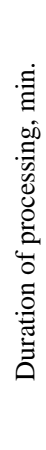 & $\begin{array}{l}b^{0} \\
3 \\
\vec{B} \\
\vec{\Xi} \\
\vec{D}\end{array}$ & 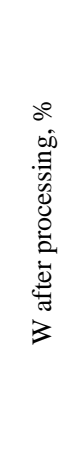 & 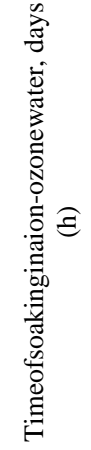 & 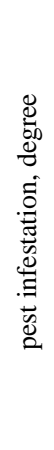 & 胥 \\
\hline Control sample & 10 & - & - & - & - & 14,6 & 44,35 & $\begin{array}{c}3 \\
(72 \mathrm{~h} .)\end{array}$ & 1 & 72 \\
\hline $\begin{array}{l}\text { Sample, processed by ion- } \\
\text { ozone explosive cavitation }\end{array}$ & 10 & 500 & 0,1 & 0,8 & 10 & 14,6 & 45 & $\begin{array}{c}0,5 \\
(12 \mathrm{~h} .) \\
\end{array}$ & 0 & 80 \\
\hline
\end{tabular}

The results of the experiment show that the moisture content of the barley grain pretreated at the ion-ozone explosive-cavitationinstallation reaches the required amount, which is $45 \%$ after 0.5 days (12 hours) in comparison to the control sample that accumulated $44.35 \%$ moisture only after 3 Days ( 72 hours). In addition, the number of mites and weevils after treatment of barley grain by ion-ozone explosive cavitation equal to zero, while the control sample has the first degree of infection with pests ( 2 weevils and 15 mites). Extractivity of barley is increased to $80 \%$.

The influence of various ion-ozone concentrations on the energy units and barley grain germination capacity upon irradiation of the grain before soaking is shown in Table 2.

TABLE II: Influence of Processing Regimes onto Energy and Germination Capacity

\begin{tabular}{|l|l|l|}
\hline $\begin{array}{l}\text { Processing regime, \% the concentration of ion } \\
\text { and ozone }\end{array}$ & Energy of germination, \% Capacity of germination, \% & ( $\%$ \\
\hline Control sample & $96,4 \%$ & $98,6 \%$ \\
\hline $4 \cdot 10^{-3}$ & $96,6 \%$ & $98,8 \%$ \\
\hline $2,03 \cdot 10^{-5}$ & $97,2 \%$ & $98,9 \%$ \\
\hline $6 \cdot 10^{-5}$ & $98,3 \%$ & $99,4 \%$ \\
\hline
\end{tabular}


As can be seen from the presented data, in all variants with treatment, a tendency towards increasing the germinating capacity of the grain has been revealed: the energy and the ability to germinate above the benchmarks.

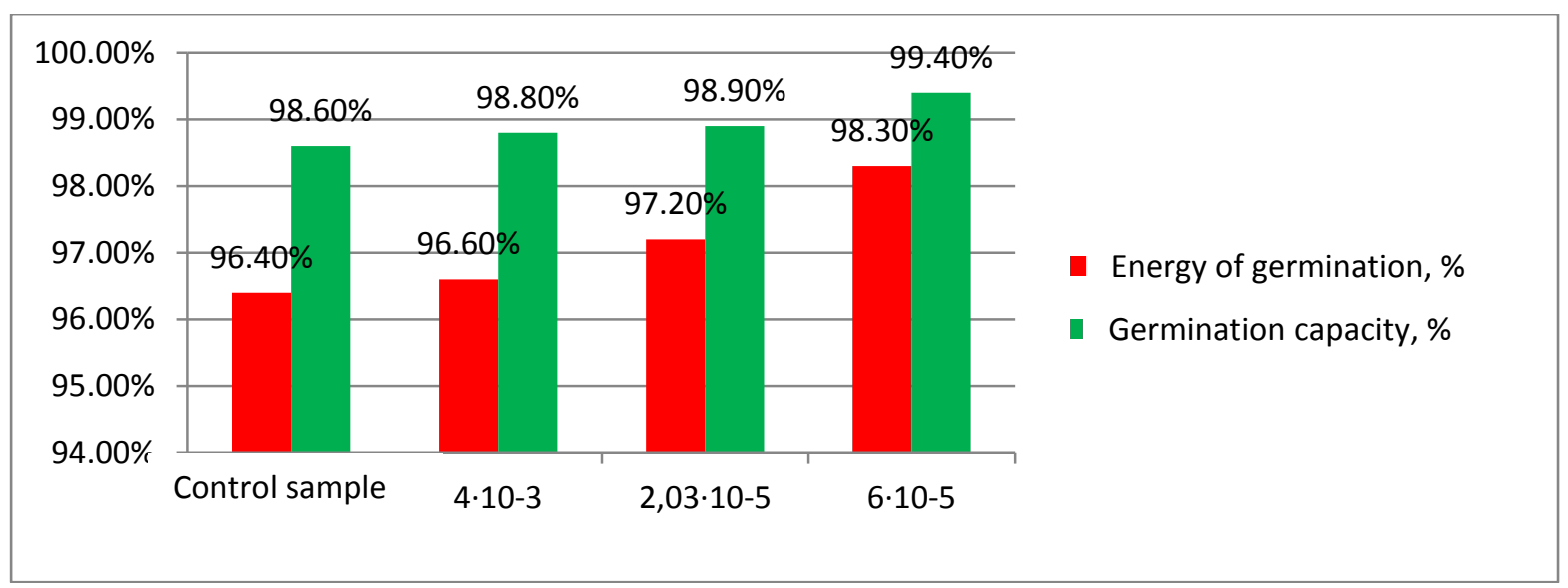

Fig. 2:Influence of Processing Regimes onto Energy and Germination Capacity

\section{Conclusion}

Analysis of the effectiveness of ion-ozone explosive treatment during the processing of barley, soaked to a moisture content of $45 \%$, revealed an increase in the ability of germination of grain in experimental variants by 0.8-1.9\% in comparison to the control samples, bringing this indicator to the parameters required by the standard.

The obtained data indicate a reduction in the duration of soaking due to the application of ion-ozone explosive cavitation. Thus, this technology allows to reducing the costs of disinfectants, to reduce the consumption of energy resources due to the fact that the shell and endosperm of barley grain are being destroyed, the grain volume is increasing, and the pores are increasing as well.

\section{References}

[1] Ermolayeva G.A . Reference book of the laboratory worker of the brewery / G.A. Ermolayeva // - St. Petersburg:Profession, 2014. - 536 p.

[2] Pavlov S.A., Golubkovich A.V. Investigation of ultrasonic grain drying processes // Energy supply and energy saving in ruralEconomy: tr. Intl. Scientific and technical. Conf. - Moscow, 2012. - T. 2. - P. 154-157

[3] MIT Technology Review. Technologies. Scientists told about the discovery, which can completely change the technology of brewing.Https://profibeer.ru/tech/13652/ 27/09/2016

[4] Application for the grant of a patent of the Republic of Kazakhstan for the invention of reg. No. $2016 / 1028.1$. Universal ion-ozone explosion cavitation installation for processing of seeds, grain and products of its processing / Maiemerov M.M., Iztaev A.I.; The date was received. 08.11.16. - 2 s. 